DOI: $10.2478 / \mathrm{v} 10129-011-0030-1$

A. Prodi ${ }^{1}$, D. Salomoni ${ }^{2}$, E. Bertacchini ${ }^{1}$, D. Alkadri ${ }^{1}$, A. Pisi $^{1}$, S. Tonti ${ }^{1,3}$, I. Alberti $^{3}$, M. Dal Prà ${ }^{3}$, D. Pancaldi ${ }^{2}$, L. Covarelli ${ }^{4}$, P. Nipoti ${ }^{1}$

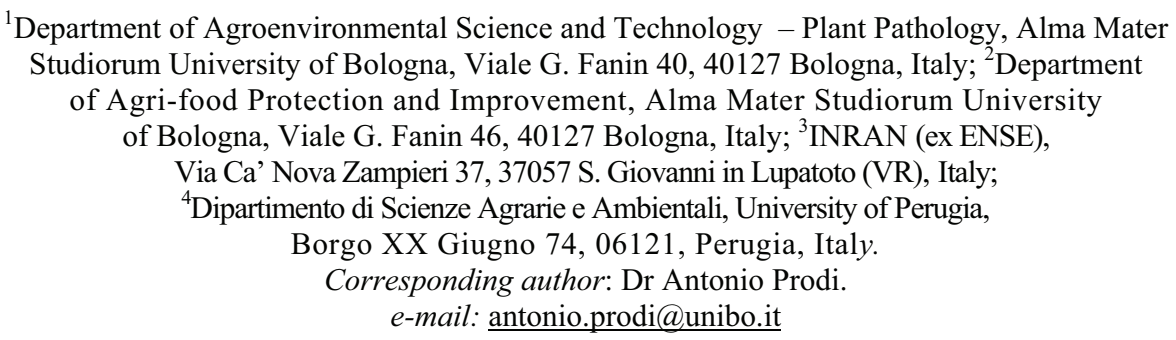

\title{
DETERMINATION OF DEOXYNIVALENOL AND NIVALENOL PRODUCING CHEMOTYPES OF FUSARIUM GRAMINEARUM ISOLATED FROM DURUM WHEAT IN DIFFERENT ITALIAN REGIONS
}

\begin{abstract}
Durum wheat production in Italy is economically of great importance. Fusarium graminearum is the main fusarium head blight (FHB) causal agent in wheat, reducing both yield and grain quality. F. graminearum produces several mycotoxins and, among trichothecenes, deoxynivalenol (DON) and nivalenol (NIV) are the most studied for their toxicity towards humans and animals. DON-producing isolates can be further distinguished on the basis of the predominant acetyl-DON derivative in 3-acetyldeoxynivalenol (3-ADON) or 15acetyldeoxynivalenol (15-ADON). In order to evaluate possible mycotoxin contamination risks in food, it is very important to know which chemotype is the prevalent in a $F$. graminearum population.

F. graminearum sensu stricto strains were collected from symptomatic durum wheat heads and grains of several naturally infected fields located mostly in Emilia - Romagna, The Marche, Lazio, Tuscany and Umbria. A multiplex PCR in the region of genes Tri12, located in the terminal gene cluster of trichothecenes, was used to characterize 187 single-spore isolates of $F$. graminearum as NIV, 3-ADON and 15-ADON chemotypes.

All the three chemotypes were present in the $F$. graminearum population studied. The most frequent chemotype was 15-ADON (83.4\%), followed by 3-ADON (10.7\%) and NIV (5.9\%). NIV-producing isolates were found only in Emilia-Romagna (3.5\%), Umbria (33.3\%) and The Marche (5.7\%).
\end{abstract}

Key words: DON and NIV chemotypes, durum wheat, Fusarium Head Blight, Tri12

Communicated by Edward Arseniuk 


\section{INTRODUCTION}

Fusarium Head Blight (FHB) of wheat has been reported for the first time in Italy at the beginning of the XX century by Peglion (1900). Since then, it has been constantly present in Italy, especially in northern and central regions, but particularly strong attacks have been recorded from 1995 (Pancaldi et al., 1996) to date. The disease is caused by several Fusarium species such as $F$. graminearum Schwabe, F. culmorum (W. G. Smith) Sacc. and F. poae (Peck) Wollenweb. (Parry et al., 1995; Shah et al., 2005; Pancaldi et al., 2010).

FHB incidence and severity are related to year and area of cultivation and to the wheat variety utilized (Pancaldi et al., 1996; Balmas et al., 2000a; Rossi et al., 2006) and its main consequences are low seed quality and mycotoxin accumulation. F. graminearum in Emilia-Romagna, from 1995 to 2007, was the most frequently isolated species from blighted heads (average incidence of $32.1 \%$ ) (Pancaldi et al., 2010). F. graminearum mainly produces deoxynivalenol (DON), a trichothecene mycotoxin that inhibits DNA, RNA and protein synthesis responsible of hemorrhagic and anorexic syndromes, neurotoxic and immunotoxic effects in mammals (Bottalico and Perrone, 2002) and which is strictly regulated in the EU (CE n. 856/2005 and updated n.1126/2007).

$F$. graminearum population can be divided into two chemotypes based on the production of the 8-ketotrichothecenes, DON and nivalenol (NIV). DONproducing isolates can be further distinguished on the basis of the predominant acetyl DON derivative that they produce; 3-acetyl DON (3-ADON) or 15-acetyl DON (15-ADON) (Miller et al., 1991; Jennings et al., 2004).

In order to evaluate possible mycotoxin contamination risks in food it can be very important to know the prevalent chemotype into a $F$. graminearum population (Quarta et al., 2005). The aim of this study was to map the chemotypes in Italy during investigations conducted from 2006 to 2009 in durum wheat fields.

\section{MATERIALS AND METHODS}

Durum wheat kernels and ears, showing the typical symptoms of FHB, of different cultivars were collected from several Italian regions. Mycological analyses were carried out by the methodology of Pancaldi et al. (2004). Plates containing potato dextrose agar (PDA) were incubated at $22^{\circ} \mathrm{C}$ in the dark for 5 days and the developed mycelium was transferred into new PDA plates under near-ultraviolet (NUV) alternating light and dark ( $12 \mathrm{~h}$ photoperiod) for 10 days to induce sporulation. The single spore cultures obtained (Balmas et al., 2000b) were identified as F. graminearum according to the morphological criteria proposed by Leslie and Summerell (2006).

The DNA of each strain was extracted using a CTAB (exadecyl-trimethylammonium bromide) method adapted from Lhodi et al. (1994) and subjected to PCR reactions to confirm that these strains belonged to $F$. graminearum sensu stricto, using specific primers under the conditions described by Nicholson et al. (1998). 
The $F$. graminearum chemotype was assigned with a multiplex version (Starkey et al., 2007) of a chemotype specific test, previously validated by Ward et al. (2002). Primers are designed in the region of genes Tri12, located in the terminal gene cluster of trichothecenes and can distinguish three subgroups, depending on the type of $\beta$-trichothecenes product. One primer is common to all chemotypes $(12 \mathrm{CON})$ and the others are chemotype-specific for 15-ADON (1215F), 3-ADON (12-3F) and NIV (12NF) (Starkey et al., 2007). PCR was carried out using the protocol reported by Prodi et al. (2009).

\section{RESULTS}

In total, 187 isolates [140 obtained in this work plus 47 previously characterized by Prodi et al. (2009)] were identified as $F$. graminearum using traditional identification techniques and all were confirmed as $F$. graminearum by speciesspecific PCR assays.

Table 1

Fusarium graminearum chemotype (\%) presence in kernels and wheat ears collected in the Italian surveyed regions.

\begin{tabular}{|c|c|c|c|c|c|c|c|c|c|c|c|c|}
\hline \multirow[t]{2}{*}{ Regions } & \multicolumn{3}{|c|}{$\begin{array}{c}\text { Number of strains } \\
\text { isolated }\end{array}$} & \multicolumn{3}{|c|}{$\begin{array}{c}\text { 15- } \mathrm{ADON} \\
{[\%]}\end{array}$} & \multicolumn{3}{|c|}{$\begin{array}{c}\text { 3- } \mathrm{ADON} \\
{[\%]}\end{array}$} & \multicolumn{3}{|c|}{$\begin{array}{l}\text { NIV } \\
{[\%]}\end{array}$} \\
\hline & K & $\mathrm{E}$ & $\mathrm{T}$ & K & $\mathrm{E}$ & $\mathrm{T}$ & K & $\mathrm{E}$ & $\mathrm{T}$ & $\mathrm{K}$ & $\mathrm{E}$ & $\mathrm{T}$ \\
\hline Emilia Romagna & 60 & 54 & 114 & 91.7 & 83.3 & 87.7 & 6.7 & 11.1 & 8.8 & 1.7 & 5.6 & 3.5 \\
\hline The Marche & 23 & 12 & 35 & 91.3 & 91.7 & 91.4 & 4.3 & 0.0 & 2.9 & 4.3 & 8.3 & 5.7 \\
\hline Umbria & 15 & & 15 & 53.3 & & 53.3 & 13.3 & & 13.3 & 33.3 & & 33.3 \\
\hline Tuscany & 7 & & 7 & 57.1 & & 57.1 & 42.9 & & 42.9 & 0.0 & & 0.0 \\
\hline Sardinia & 4 & & 4 & 100.0 & & 100.0 & 0.0 & & 0.0 & 0.0 & & 0.0 \\
\hline Lombardy & 4 & & 4 & 50.0 & & 50.0 & 50.0 & & 50.0 & 0.0 & & 0.0 \\
\hline Lazio & 2 & & 2 & 0.0 & & 0.0 & 100.0 & & 100.0 & 0.0 & & 0.0 \\
\hline Piedmont & 2 & & 2 & 100.0 & & 100.0 & 0.0 & & 0.0 & 0.0 & & 0.0 \\
\hline Campania & 1 & & 1 & 100.0 & & 100.0 & 0.0 & & 0.0 & 0.0 & & 0.0 \\
\hline \multirow[t]{2}{*}{ Veneto } & 1 & 2 & 3 & 100.0 & 100.0 & 100.0 & 0.0 & 0.0 & 0.0 & 0.0 & 0.0 & 0.0 \\
\hline & & & 187 & & & 83.4 & & & 10.7 & & & 5.9 \\
\hline
\end{tabular}

$\mathrm{K}$ - kernels; E - ears; T - total

The percentages of the three chemotypes found in kernels and ears for each region are reported in Table 1. All the three chemotypes were present in the $F$. graminearum population considered in this study. The most frequently isolated chemotype was $15-\mathrm{ADON}$ (83.4\%), followed by 3 -ADON $(10.7 \%)$ and NIV (5.9\%). 15-ADON-producing isolates were found in all the Italian regions but Lazio, where $2 / 2$ strains were 3-ADON. 3-ADON seemed to be more present in Lombardy and Tuscany than in other regions. NIV-producing isolates were 
found only in Emilia-Romagna (3.5\%), Umbria (33.3\%) and The Marche $(5.7 \%)$.

\section{DISCUSSION AND CONCLUSIONS}

In the recent years, in several wheat growing Italian areas, DON has been constantly found in FHB infected kernels of durum and bread wheat (Lops et al., 1998; Pascale et al., 2002; Rossi et al., 2006). In the 2007-2008 growing season, DON levels in many durum wheat samples exceeded the legal limits in Emilia-Romagna (Rossi, 2008). Knowledge on the distribution of Fusarium chemotypes is considered effective on a regional basis to predict a possible mycotoxin contamination (Jennings et al., 2004); Pasquali et al. (2010) reported that chemotyping is a useful tool for predicting nivalenol contamination in winter wheat.

Our data on chemotype frequency are comparable with those reported by several authors in the world. In different USA areas, Gale et al. (2007) identified $15-\mathrm{ADON}$ as the prevailing chemotype of $F$. graminearum sensu stricto, followed by $3-\mathrm{ADON}$ (5.1\% of total), and one to NIV chemotype. In southern Russia $90 \%$ of the isolates was 15-ADON (Yli-Mattila et al., 2008), in England and Wales, Jennings et al. (2004) found DON (75\%) and NIV (25\%) with the predominant $15-\mathrm{ADON}$ chemotype $(95 \%)$, in Luxembourg the $15-\mathrm{ADON}$ chemotype was the major population $(94.3 \%)$, the 3-ADON chemotype was not detected and the NIV chemotype was detected sporadically (5.8\%) (Pasquali et al.,2010). To our knowledge, only another research, performed on a very few $F$. graminearum Italian strains collected from 8 different regions, indicated that $58 \%$ of the analyzed isolates were $15-\mathrm{ADON}$, while both $3-\mathrm{ADON}$ and NIV were present at $21 \%$ (Gale et al., 2007). Results on NIV chemotypes do not correspond to those obtained in the present study where they averaged at $5.9 \%$ and where they showed a high incidence $(33.3 \%)$ only in Umbria. The results, presented by Ward et al. (2008), show how a population of $F$. graminearum with 3 -ADON chemotype replaced the dominant $15-\mathrm{ADON}$ population in western Canada, evidencing a selective advantage. This was confirmed by Guo et al. (2008) that showed that in Manitoba, the 15-ADON chemotype remains predominant, but the 3-ADON had an increase trend in the southern part of the examined region. This fact was not due to the capacity of the 3-ADON strains to produce an higher level of DON, because DON production was significantly higher only on the susceptible cultivar and not on moderately or resistant wheat cultivars and, therefore, DON production was not correlated with higher aggressiveness (Ward et al., 2008, von der Ohe et al., 2010).

In China, the situation is much more complicated for the simultaneous presence of $F$. graminearum lineage 7 (sensu stricto) and $F$. graminearum lineage 6 $(F$. asiaticum), this last lineage not being present in Europe and USA (Ji et al., 2007). Qu et al. (2008a) found that $F$. asiaticum was more frequent in warmer 
regions while $F$. graminearum sensu stricto was significantly present in cooler regions.

In this study the consistent population of $F$. graminearum, collected in Italian areas exclusively isolated from durum wheat, showed a chemotyping similar to that observed in other geographical areas. The continuous expansion of durum wheat cultivation in Italy will permit to increase the collection of $F$. graminearum strains from this important food crop in order to obtain more accurate information on the frequency and geographical distribution of isolates with different mycotoxin production and to identify the Italian areas exposed to the mycotoxin risk.

\section{ACKNOWLEDGMENTS}

The authors would like to thank the INRAN, section of Bologna, for field technical support, Dr V. Balmas (Università di Sassari) and Dr A. Infantino (CRA-PAV, Rome) for providing the F. graminearum strains from Sardinia and Lazio, respectively.

\section{REFERENCES}

Balmas V., Vitale S., Marcello A., Corazza L. 2000a La fusariosi della spiga. L'informatore Agrario 35 Supplemento: 27-29.

Balmas V., Santori A., Corazza L. 2000b Le specie di Fusarium più comuni in Italia. Petria 10, suppl. 1: 1-60.

Bottalico A., Perrone G. (2002) Toxigenic Fusarium species and mycotoxins associated with head blight in small-grain cereals in Europe. Eur J of Plant Pathol 108: 611-624.

Gale L.R., Ward T.J., Balmas V., Kistler H.C. 2007 Population subdivision of Fusarium graminearum sensu stricto in the upper Midwestern United States. Phytopathology 97: 1434-1439.

Guo X.W., Fernando W.G.D., Seow-Brock H.Y. 2008 Population structure, chemotype diversity, and potential chemotype shifting of Fusarium graminearum in wheat fields of Manitoba. Plant Disease 92 (5): 756 -762 .

Jennings P., Coates M.E., Walsh K., Turner J.A., Nicholson P. 2004 Determination of deoxynivaleonl- and nivalenol-producing chemiotypes of Fusarium graminearum isolated from wheat crops in England and Wales. Plant Pathology 53: 643-652.

Ji L., Cao K., Hu T., Wang S. 2007 Determination of Deoxynivalenol and Nivalenol chemotypes of Fusarium graminearum isolates from China by PCR assay. Journal of Phytopathology 155: 505-512.

Leslie J.F., Summerell B.A. 2006 The Fusarium Laboratory Manual. Blackwell Publishing, Ames, U.S.A: pp. 388

Lohdi M.A., Ye G., Weeden F., Reisch B.I. 1994 A simple and efficient method for DNA extraction from grapevine cultivars and Vitis species. Plant Molecular Biology Reporter 12: 6-13.

Lops R., Pascale M., Pancaldi D., Visconti A. 1998. Infezioni fungine e presenza di deossinivalenolo in cariossidi di frumento prodotte in diverse regioni italiane. Inf.tore fitopatologico 48 (4): 60-66.

Miller J.D., Greenhalgh R., Wang Y.Z., Lu M. 1991 Trichothecene chemotypes of three Fusarium species. Mycologia 83: 121-130.

Nicholson P., Simpson D.R., Weston G., Rezanoor H.N., Lees A.K., Parry D.W., Joyce D. 1998 Detection and quantification of Fusarium culmorum and Fusarium graminearum in cereals using PCR assays. Physiological and Molecular Plant Pathology 53: 17-37.

Pancaldi D., Grazzi G., Alberti I. 1996 La fusariosi della spiga di frumento in Emilia Romagna nel 1995. Informatore fitopatologico 46 (4): 16-20.

Pancaldi D., Pisi A., Alberti I., Romani S. 2004 Control of Fusarium head blight and accumulation of deoxynivalenol in durum wheat grain, semolina and bran. Phytopathol Medit 43: 351-359. 
Pancaldi D., Tonti S., Prodi A., Salomoni D., Dal Prà M, Nipoti P., Alberti I., Pisi A. 2010. Survey of the main causal agents of fusarium head blight of durum wheat - Bologna - Northern Italy. Phytopathologia mediterranea 49 (2), 258-266

Parry D.W., Jenkinson P., McLeod L. 1995 Fusarium ear blight (scab) in small grains - a review. Plant Pathol. 44: $207-238$

Pascale M., Bottalico A., Pancaldi D., Perrone G., Visconti A. 2002 Occurrence of deoxynivalenol in cereals from experimental fields in various Italian regions. Petria 12, 123-129.

Pasquali M., Giraud F., Brochot C., Cocco E., Hoffmann L., Bohn T. 2010 Genetic Fusarium chemotyping as a useful tool for predicting nivalenol contamination in winter wheat Int J Food Microbiol. 137, 246-253.

Peglion V. 1900 Sulla cosidetta "Golpe Bianca" del frumento. Bollettino Notiziario Agrario 20, 17-26.

Prodi A., Tonti S., Nipoti P., Pancaldi D., Pisi A. 2009 Identification of deoxynivalenol and nivalenol producing chemotypes of Fusarium graminearum isolates from durum wheat in a restricted area of northern Italy. J of Plant Pathol 91 (3): 611-615.

Qu B., Li H.P., Zhang J.B., Xu J.B., Huang T., Wu A.B., Zhao C.S., Carter J., Nicholson P., Liao Y.C. 2008. Geographic distribution and genetic diversity of Fusarium graminearum and $F$. asiaticum on wheat spikes throughout China. Plant Pathology 57: 15-24.

Quarta A., Mita G., Haidukowski M., Santino A., Mulè G., Visconti M. 2005 Assesment of trichothecene chemotypes of Fusarium culmorum occurring in Europe. Food Additives and Contaminants 22(4): 309315 .

Rossi V., Giosuè S., Cigolini M., Delogu G., Faccini N., Terzi V., Scudellari D. 2006 Un aiuto alla gestione della fusariosi della spiga. L'Inf.tore Agrario, 62 (14): 62-68.

Rossi V. 2008 La Fusariosi della spiga: una annata favorevole alla malattia che conferma però l'affidabilità dei sistemi di previsione. Filiera Grano duro news 8: 2 .

Shah D.A., Pucci N., Infantino A. 2005. Regional and varietal differences in the risk of wheat seed infection by fungal species associated with fusarium head blight in Italy. Eur J of Plant Pathol 112: 13-21.

Starkey D.E., Ward T.J., Aoki T., Gale L.R., Kistler H.C., Geiser D.M., Suga H., Toth B., Varga J., O’Donnell K. 2007. Global molecular surveillance reveals novel Fusarium head blight species and trichothecene toxin diversity. Fungal genetics and biology 44(11): 1191-1204.

Ohe C.,von der Gaunther V., Tamburic-Illincic L., Brule-Babel A., Fernando W.G.D., Clear r., Ward T.J., Miedaner T. 2010 A comparison of aggressiveness and Deoxynivalenol production between Canadian Fusarium graminearum isolates with 3-acetyl and 15-acetyldeoxynivalenol chemotypes in field-grown spring wheat. Eur J Plant Pathol 127: 407-417.

Ward T.J., Bielawski J.P., Kistler H.C., Sullivan E., O’Donnell K. 2002. Ancestral polymorphism and adaptive evolution in the trichothecene mycotoxin gene cluster of phytopathogenic Fusarium. Proceedings of the National Academy of Sciences of the USA 99: 9278-9283.

Ward T.J., Clear R.M., Rooney A.P., O'Donnell K., Gaba D., Patrick S., Starkey D.E., Gilbert J., Geiser D.M., Nowicki T.W. 2008. An adaptive evolutionary shift in Fusarium head blight pathogen populations is driving the rapid spread of more toxigenic Fusarium graminearum in North America. Fungal Genetics and Biology 45: 473-484.

Yli-Mattila T., O'Donnell K., Ward T., Gagkaeva T. 2008. Trichotecene chemotype composition of Fusarium graminearum and related species in Finland and Russia. J of Plant Pathol 90 (3): S 3.60. 